\title{
Limitations in dose-response and surrogate species methodologies for risk assessment of Cry toxins on arthropod natural enemies
}

\author{
Débora P. Paula ${ }^{1}$ - David A. Andow ${ }^{2} \cdot$ André Bellinati $^{1,3} \cdot$ Renata Velozo Timbó $^{1,3}$ \\ Lucas M. Souza ${ }^{1}$ - Carmen S. S. Pires ${ }^{1} \cdot$ Edison R. Sujii $^{1}$
}

Accepted: 27 January 2016/Published online: 4 February 2016

(C) Springer Science+Business Media New York 2016

\begin{abstract}
Dose-response assays and surrogate species are standard methods for risk analysis for environmental chemicals. These assume that individuals within a species have unimodal responses and that a surrogate species can predict responses of other related taxa. We exposed immature individuals of closely related aphidophagous coccinellid predators, Cycloneda sanguinea and Harmonia axyridis, to Cry $1 \mathrm{Ac}$ and Cry $1 \mathrm{~F}$ toxins through uniform and constant artificial tritrophic exposure through Myzus persicae aphids. Both toxins were detected in coccinellid pupae, with individual and interspecific variation. Uptake was significantly higher in $H$. axyridis than in $C$. sanguinea, both in the proportion of individuals and the concentrations per individual. We also observed bimodal uptake of the Cry toxins by $H$. axyridis, which indicated that some individuals had low bioaccumulation and some had high bioaccumulation. This suggests that standard dose-response assays need to be interpreted with caution and future assays should examine the modality of the responses. In addition, the similarity in the biological effects of the Cry toxins in the two predators was due to
\end{abstract}

Electronic supplementary material The online version of this article (doi:10.1007/s10646-016-1619-9) contains supplementary material, which is available to authorized users.

Débora P. Paula

debora.pires@embrapa.br

1 Embrapa Genetic Resources and Biotechnology, Parque Estação Biológica, W5 Norte, P.O. Box 02372, Brasília, DF 70770-917, Brazil

2 Department of Entomology, University of Minnesota, 219 Hodson Hall, 1980 Folwell Ave., St. Paul, MN 55108, USA

3 University of Brasília, Campus Universitário Darcy Ribeiro, Brasília, DF, Brazil different biological exposure mechanisms. The majority of $H$. axyridis were exposed both internally and in the gut, while $C$. sanguinea was exposed primarily in the gut. Thus, despite their close phylogenetic relatedness, these species would not be good surrogates for each other and the surrogate species methodology should be tested more rigorously.

Keywords Coccinellid · GM crops $\cdot$ Predator $\cdot$ Surrogacy

\section{Introduction}

Many studies have been conducted to evaluate the direct or indirect effects of Cry toxins expressed by genetically modified (GM) plants on non-target beneficial insects, such as natural enemies, due to their important ecosystem service of pest regulation. The primary method to evaluate non-target effects has been based on quantifying a "doseresponse relationship" through bi- and tritrophic exposure (Groot and Dicke 2002) on a small number of surrogate species, and extrapolating the results to broader taxa of interest (Garcia-Alonso et al. 2006; Suter 2007; Romeis et al. 2008). This relies on two key assumptions: individual responses to uniform and constant exposure are unimodal, and the surrogate accurately predicts responses of other taxa. The unimodal response presumption has not been evaluated for non-target effects of GM plants, and extrapolation based on surrogate species has been shown to be inaccurate (Suter 2007; Banks et al. 2014) and imprecise (Elmegaard and Akkerhuis 2000).

In the last 15 years, laboratory studies have demonstrated that some natural enemy species can uptake and even bioaccumulate Cry toxins delivered from their prey (Couty et al. 2001; Zhang et al. 2006; Gao et al. 2010; 
Paula and Andow 2015). Uptake is the absorption of a chemical from the food (USEPA 2013), i.e. the continued presence of a toxin after exposure has stopped and gut contents eliminated. However, there are no studies comparing the variability in the uptake of Cry toxins by a natural enemy species and by a closely related one, and its possible ecological significance. Of course, all published studies in this area report variation in presence of Cry toxins among individuals as error, and they assume that the variation is unimodal and without biological meaning. If the variation in uptake of Cry toxins by a natural enemy is instead multimodal, then accurate interpretation of doseresponse experiments requires examination of the modality of the response. Moreover, if there is a large difference in uptake of Cry toxins between closely related natural enemy species, then the species will not be good surrogates for each other, because they have different exposure and effects mechanisms (Lewis 1995; Godoy et al. 2015).

To test the robustness of the dose-response and surrogate species methodologies for risk assessment of Cry toxins on insect pest natural enemies, we exposed two closely related coccinellid aphidophagous predator species using an artificial tritrophic system with uniform and constant concentration of Cry toxins. We investigated how much variability in uptake of the Cry toxins occurs among individuals from the same species and across closely related species, and compared the population responses of related species to evaluate how well one can act as a surrogate for the other.

\section{Methods}

\section{Insect rearing}

The prey aphid, Myzus persicae (Hemiptera: Aphididae), was reared on collard plants in a greenhouse at $13 \mathrm{~h}$ photophase at $25 \pm 4{ }^{\circ} \mathrm{C}$ at $60 \pm 10 \%$ RH. The aphidophagous predators Cycloneda sanguinea and Harmonia axyridis (Coleoptera: Coccinellidae) are common in Brazil and were chosen because they are closely related in the same tribe, Coccinellini (Giorgi et al. 2008). They were reared in plastic cages, $10 \times 15 \mathrm{~cm}$, containing a daily supply of water in wet cotton balls and leaves containing aphids collected from the field. Their egg masses were transferred to separate cages and inspected daily to collect the neonate larvae (less than $24 \mathrm{~h}$ old) for use in the bioassays.

\section{Bioassay preparation}

The trypsinized and purified Cry1Ac and Cry1F toxins (both ca $65 \mathrm{kDa}$ ) were purchased from Dr. M. Pusztai-
Carey (Department of Biochemistry, Case Western Reserve University, Cleveland, Ohio) and their biological activities were confirmed in tests against caterpillars of Anticarsia gemmatalis (Lepidoptera: Noctuidae) as described in Nakasu et al. (2013). The Cry toxins were solubilized in a $50 \mathrm{mM} \mathrm{Na} \mathrm{Na}_{3}$ solution containing $100 \mathrm{mM} \mathrm{NaCl}, \mathrm{pH} 10$ with $10 \mathrm{mM}$ dithiothreitol added before use. This solution was added to a liquid holidic diet for aphids (Dadd and Mitter 1996), which was sterilized by filtration at $0.22 \mu \mathrm{m}$ in a laminar flow hood. This diet $(150 \mu \mathrm{l})$ was placed in a sterilized sachet of two pieces of stretched Parafilm $M$ attached to one end of a $25 \mathrm{~mm}$ acrylic tubular cage (Douglas and van Emden 2007). Between 10 and 50 aphids were transferred to each cage, according to the predator instar, to feed on the diet of each treatment (see below) for at least $24 \mathrm{~h}$ before exposure to the predators in the bioassays (Wright et al. 1985). Cages with aphids were provided daily to the predators. All bioassays were conducted inside a controlled environment chamber $\left(25 \pm 2{ }^{\circ} \mathrm{C}\right.$ and $13 \mathrm{~h}$ photophase).

\section{Exposure of larval predators}

Unfed neonate predator larvae were individually transferred to cages containing $M$. persicae aphids feeding on diet of one of the treatments: 1. Control (no Cry toxin added); 2. Cry1Ac $20 \mu \mathrm{g} / \mathrm{ml}$ (C20); 3. Cry1F $20 \mu \mathrm{g} / \mathrm{ml}$ (F20); 4. Cry1Ac $20+$ Cry1F $20 \mu \mathrm{g} / \mathrm{ml}$ (C20:F20); 5. Cry1Ac $20+$ Cry1F $70 \mu \mathrm{g} / \mathrm{ml}$ (C20:F70); and 6. Cry1Ac $70+$ Cry1F $20 \mu \mathrm{g} / \mathrm{ml}$ (C70:F20). These Cry1Ac and Cry1F concentrations were similar to that in leaves of WideStrike ${ }^{\circledR}$ cotton (Siebert et al. 2009), and were chosen to investigate the possibility of synergisms between the toxins. Water was supplied daily in each cage on wet filter paper $\left(1 \mathrm{~cm}^{2}\right)$. The cages were inspected daily until the pupal stage to evaluate survival and developmental stage. Pupae (within $24 \mathrm{~h}$ of pupation) were weighed and stored at $-20{ }^{\circ} \mathrm{C}$ for ELISA.

\section{Cry1Ac and Cry1F detection}

The Cry toxins were detected and quantified using enzymelinked immunosorbent assay (ELISA). We measured the concentrations in undiluted diet to confirm toxin concentrations (see Supplementary Material, SM-1). To determine if CrylAc and Cry1F decayed in the diets during the experiment, toxin was quantified in paired diets 24 and $72 \mathrm{~h}$ after diet addition to the cages with three technical replicates for each diet cage. In addition, for each diet at least six replicates of $100 \mathrm{M}$. persicae were fed for $24 \mathrm{~h}$, collected and weighed for Cry quantification. All predators from the two bioassays described above were analyzed individually. All insect samples were macerated using a 
glass pestle and homogenized in PBST in a volume (in $\mu \mathrm{l}$ ) corresponding to $70 \times$ the fresh weight $(\mathrm{FW}$ ) (in $\mathrm{mg}$ ) to normalize the amount of total protein across samples. The samples were centrifuged at $15,500 \times g$ for $15 \mathrm{~min}$ and the supernatant was used for the analysis. Each sample was applied $(100 \mu \mathrm{l} /$ well $)$ in duplicate or triplicate technical replicates on a double sandwich ELISA PathoScreen plate (Agdia, USA) for Cry1 Ac and Cry1F detection and quantification according to manufacturer's instructions. Cry1 Ac and Cry $1 \mathrm{~F}$ from the same source as used in the bioassays at $0,0.0625,0.125,0.25,0.5$, and $1.0 \mathrm{ng} /$ well were used as calibration standards on each plate. All standards were replicated in duplicate on each plate and a linear calibration curve was estimated for each plate separately. For each toxin, we averaged the slopes of the calibration curves across plates to estimate toxin concentrations from observed absorbances. The absorbance was measured at $630 \mathrm{~nm}$ with a microtiter plate reader (TP Reader NM Thermo Plate ${ }^{\circledR}$, USA).

The limit of detections (LODs) for Cry1Ac and Cry1F detection in the predator samples were calculated using the standard deviation and slope method. The Cry1Ac LOD was $0.0016 \mathrm{ng} / \mathrm{mg}$ FW based on 19 predator samples tested in duplicate, and the Cry1F LOD was $0.0004 \mathrm{ng} / \mathrm{mg} \mathrm{FW}$ based on 29 predator samples tested in duplicate. Based on the dilutions and the technical specifications of the reader, the linear part of the standard curve indicated accurate estimations for the predator samples of Cry1Ac up to $5 \mathrm{ng} /$ $\mathrm{mg}$ FW and for CrylF up to $20 \mathrm{ng} / \mathrm{mg}$ FW.

\section{Statistical analysis}

Each ELISA plate was set up to contain multiple blanks, standards and controls that matched the aphid and predator samples of each Cry treatment. ELISA absorbances for each well with a sample (diets, aphids, and predator pupae) were normalized for each plate by subtracting the mean of the blanks. Then the corresponding normalized, averaged controls on each plate were subtracted from each of these normalized samples. Technical replicates were averaged to estimate the absorbance for each Cry treatment sample. These absorbances were transformed to concentrations of Cry toxin (ng of Cry/mg FW) using the average slope of the standard curve. The mean concentration of Cry toxin was calculated for each species by averaging values for all individuals in a treatment. Total sample sizes for each of the statistical analyses are provided in the Supplementary Material.

To determine the proportion of positive samples, standard errors and degrees of freedom for each individual sample were estimated from the standard deviations of the blanks, controls and technical replicates using the WelchSatterthwaite formula, which allows that the respective variances for the blanks, controls and technical replicates are not equal. Positive presence of Cry toxin was determined using Welch's $t$ test (for unequal sample size and unequal variance). The proportion of positive samples and larval survival were analyzed using logistic regression (Proc Genmod, SAS 9.4). Standard deviations for the proportion of positive samples were estimated using the Wilson score interval.

Differences in the proportion of positive samples among the species were compared using the $z$-approximation (SAS 9.4), and differences among Cry treatments were compared using a priori linear contrasts for unequal sample sizes. For Cry1Ac the contrasts were: 1. C70:F20 versus the others (to test if a higher concentration of Cry1Ac had a higher detection rate); 2. C20 versus the mean of C20:F20 and C20:F70 (to test if the presence of Cry1F influenced the detection of Cry1 Ac); and 3. C20:F20 versus C20:F70 (to test if the concentration of Cry $1 \mathrm{~F}$ influenced detection of Cry1Ac). Analogous contrasts were examined for Cry1F detections. Survival rate of predators for the entire larval period were analyzed using Proc Genmod.

Cry concentrations were analyzed using ANOVA with the same a priori linear contrasts (Proc GLM, SAS 9.4) as described above. Differences among species were analyzed by Tukey's HSD. Development time (from time of hatch to time of pupation) and pupal weight of the predators was also analyzed using Proc GLM. All sufficient statistics for all of the logistic regressions and ANOVAs are provided in the Supplementary Material.

The correlation between Cry1Ac and Cry1F concentrations in individual predators was examined using the corrected absorbances for each Cry treatment sample. All individuals from the C20:F70 diets were excluded and only individuals with positive detection of either Cry1Ac or Cry1F were included because including the individuals from the C20:F70 diets or those negative for both toxins inflated the correlations. Pearson's correlation coefficient was calculated and the Fisher transformation was used to test statistical significance.

In addition, the distributions of the estimated Cry concentrations for each predator species from the treatments with $20 \mu \mathrm{g}$ toxin/ml in the aphid diet were tested for bimodality by fitting one or two gamma distributions to the data and testing the improvement with the small sample Akaike information criterion $\left(\Delta \mathrm{AIC}_{\mathrm{c}}\right)$ using Mathematica 8 . This bimodality test was used to determine if the individuals from a predator species came from a homogeneous population with an unimodal distribution or from a heterogeneous population with a bimodal distribution. 


\section{Results}

\section{Differential uptake of the Cry toxins}

The diet concentrations of Cry toxins did not change between 24 and $72 \mathrm{~h}$ (Cry1Ac: $t_{6}=-1.80, P=0.115$; Cry1F: $t_{4}=0.65, P=0.543$, see SM-1). Cry toxins were detected in the prey and predators in all Cry treatments, although not in all samples (Fig. 1, SM-2). Cry1Ac and Cry $1 \mathrm{~F}$ were detected more frequently in $H$. axyridis pupae (Cry1Ac, $P=1.30 \times 10^{-5}$; Cry1F, $P=0.0002$ ) than in C. sanguinea pupae. About 74 and $70 \%$ of $H$. axyridis pupae had Cry $1 \mathrm{Ac}$ and Cry1F respectively, while only 9 and $14 \%$ of $C$. sanguinea did. The detection of the toxins in the predator pupae is a proof of uptake (Paula and Andow 2015), as prior to pupation, insects like coccinellids empty their guts, and during pupation they shed both the external cuticle and the cuticular lining of the gut (Chapman 1998). Thus, most $H$. axyridis were exposed internally to Cry toxins, while most $C$. sanguinea were not.

Although the exposure to the toxins via the aphid food was the same, $H$. axyridis pupae had higher concentrations of Cry1Ac and Cry1F than C. sanguinea pupae (Cry1Ac, $P<0.00005$; Cry1F, $P=0.0001$ ), and also higher than
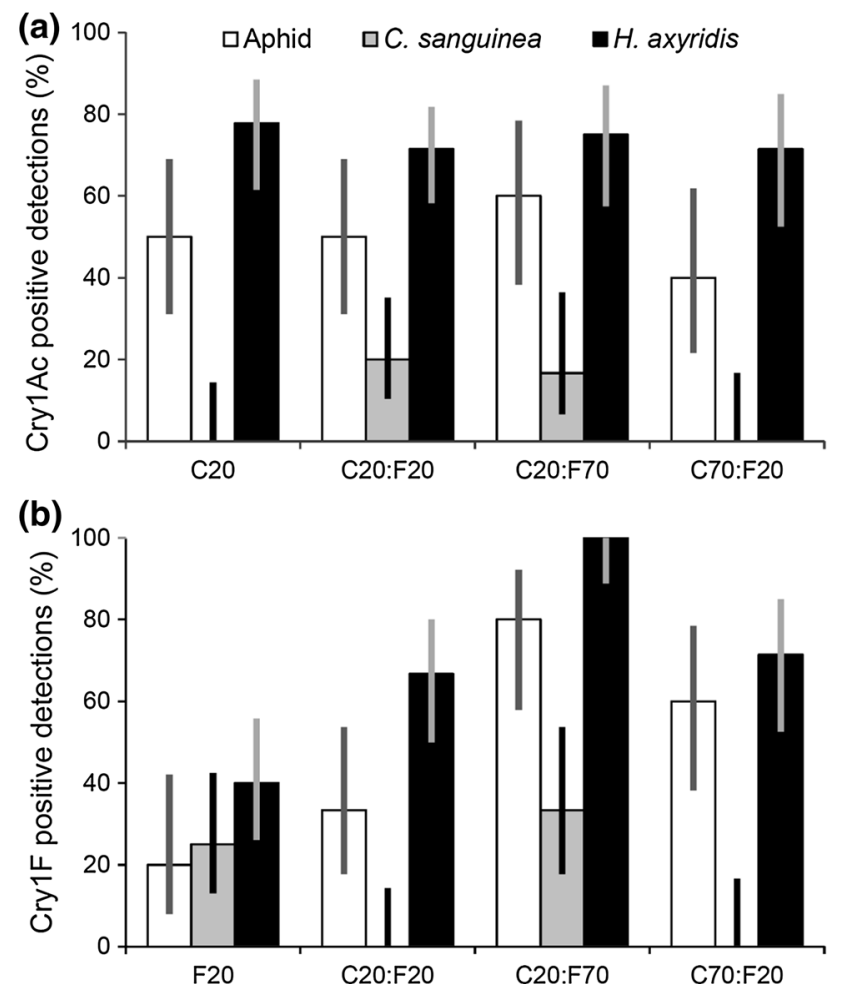

Fig. 1 Percent of positive Cry detections by ELISA in the aphid prey and predator pupae (mean $\pm \mathrm{SE}$ ): a Cry1Ac in different concentrations, with and without Cry $1 \mathrm{~F}$; b Cry $1 \mathrm{~F}$ in different concentrations, with and without Cry1Ac the prey $M$. persicae (Cry1Ac, $P=0.0119$; Cry1F, $P=0.0062$ ) (Fig. 2, SM-3). This indicates bioaccumulation of the toxins in $H$. axyridis (Bryan 1979; Paula and Andow 2015). The Cry1Ac and Cry1F concentrations were not different in $C$. sanguinea pupae and the prey $M$. persicae (Cry1Ac, $P=0.2246$; Cry1F, $P=0.6082$ ), indicating no bioaccumulation in $C$. sanguinea. The predator pupae and prey had their highest concentrations of Cry $1 \mathrm{~F}$ when exposed to the C20:F70 treatment (Fig. 2b, $P=2.07 \times 10^{-9}$ ). While $H$. axyridis had a much higher Cry1F concentration in C20:F70 treatment compared to the F20 treatments, C. sanguinea did not (Fig. 2b).

\section{Bimodality in Cry toxin uptake}

Among the $H$. axyridis pupae that were exposed to both toxins during the full larval period, those that had a higher concentration of Cry $1 \mathrm{~F}$ also had a higher concentration of Cry1Ac (Fig. 3a, SM-4, $P=0.0007$ ). While the $H$. axyridis were derived from a seemingly homogeneous source population, individuals showed substantial differences in the uptake of Cry toxins (bimodally distributed). Therefore, two kinds of $H$. axyridis individuals were observed: ones that had high concentrations of both toxins and ones that had no or low toxin (Fig. 4, SM-5, bimodal distributions, Cry1Ac, $P=0.0116$; Cry1F, $P=0.0009)$. Although a similar correlation in the uptake of the two toxins was also
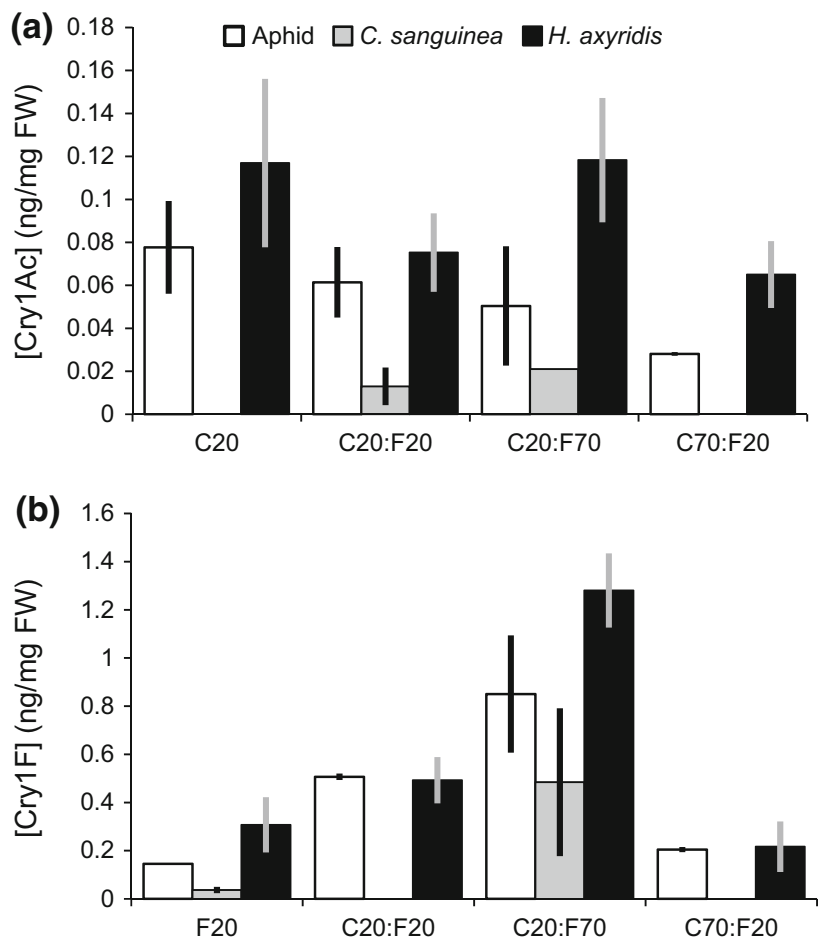

Fig. 2 Concentration (mean $\pm \mathrm{SE}$ ) in the aphid prey and predator pupae of a Cry1Ac in different concentrations, with and without Cry $1 \mathrm{~F}$; b Cry $1 \mathrm{~F}$ in different concentrations, with and without Cry1 Ac 

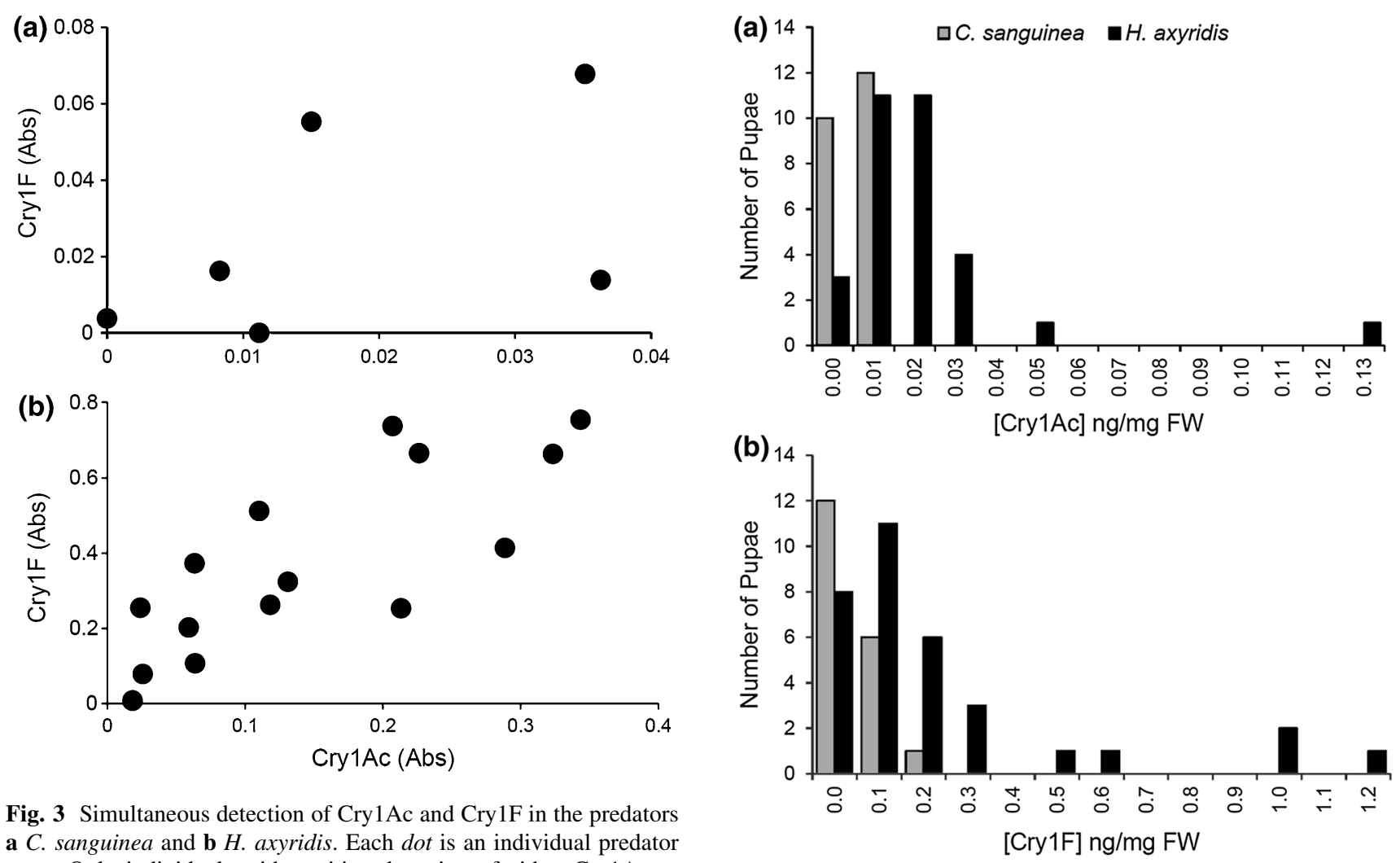

Fig. 3 Simultaneous detection of Cry1 Ac and Cry1F in the predators a $C$. sanguinea and $\mathbf{b} H$. axyridis. Each dot is an individual predator pupa. Only individuals with positive detection of either Cry1Ac or Cry $1 \mathrm{~F}$ are displayed

seen for $C$. sanguinea, it was not significant probably due to the small sample size (Fig. $3 \mathrm{~b}, P=0.493$ ). In contrast to $H$. axyridis, only one kind of $C$. sanguinea was observed (Fig. 4, unimodal distributions, Cry1Ac, $P=0.1935$; Cry1F, $P=0.8976)$.

\section{Similar ecological effects in related predators}

Cry1Ac and Cry1F, separately or combined, did not have any detectable ecological effects on either predator (Fig. 5, SM-6). Development time $(P=0.088)$, pupal fresh weight $(P=0.222)$, and larval survival rate $(P=0.553)$ did not differ among the treatments for the predator species.

\section{Discussion}

Despite using a constant exposure system, we demonstrated individual variation in uptake of Cry toxins by the predaceous coccinellids in all of the diet treatments, and also interspecific variation between the related predator species. The observed variation might have several causes, including variation in delivery of the Cry toxins from the prey, and a differential ability within and across species to uptake the Cry proteins, although the former is unlikely to

Fig. 4 Histograms of concentrations of a Cry1Ac in individuals of two species of predators, $C$. sanguinea and $H$. axyridis, and $\mathbf{b}$ Cry $1 \mathrm{~F}$ in individuals of the same species

be the main cause. While some of the aphid samples did not have detectable Cry toxin, new aphids were provided almost every day. So predators were exposed via aphids during the bioassay at an estimated average daily exposure of $0.028 \pm 0.010 \mathrm{ng}$ Cry $1 \mathrm{Ac} / \mathrm{mg}$ aphid FW, and $0.111 \pm 0.059$ and $0.680 \pm 0.170 \mathrm{ng}$ Cry $1 \mathrm{~F} / \mathrm{mg}$ aphid FW for the F20 and F70 diets respectively (Fig. 3). This resulted in a total cumulative exposure during the entire larval stage (Table 1) at least three orders of magnitude higher than the LOD. In addition, the standard error for the estimated total cumulative exposure (Table 1) was small enough that all individuals were likely to be exposed to close to this estimated level.

Thus, the main cause of the observed variation in uptake of Cry toxins within and between predator species is a differential ability to uptake the Cry toxins. With regard to the within species variation, the bimodal distributions for $H$. axyridis for both Cry1 Ac and Cry1F showed that there were two groups of individuals, one with low uptake and bioaccumulation and one with high uptake and bioaccumulation. Those with high uptake simultaneously had high uptake of both Cry toxins. The bimodal uptake of Cry toxins by $H$. axyridis suggests that published literature about standard dose-response assays should be interpreted 

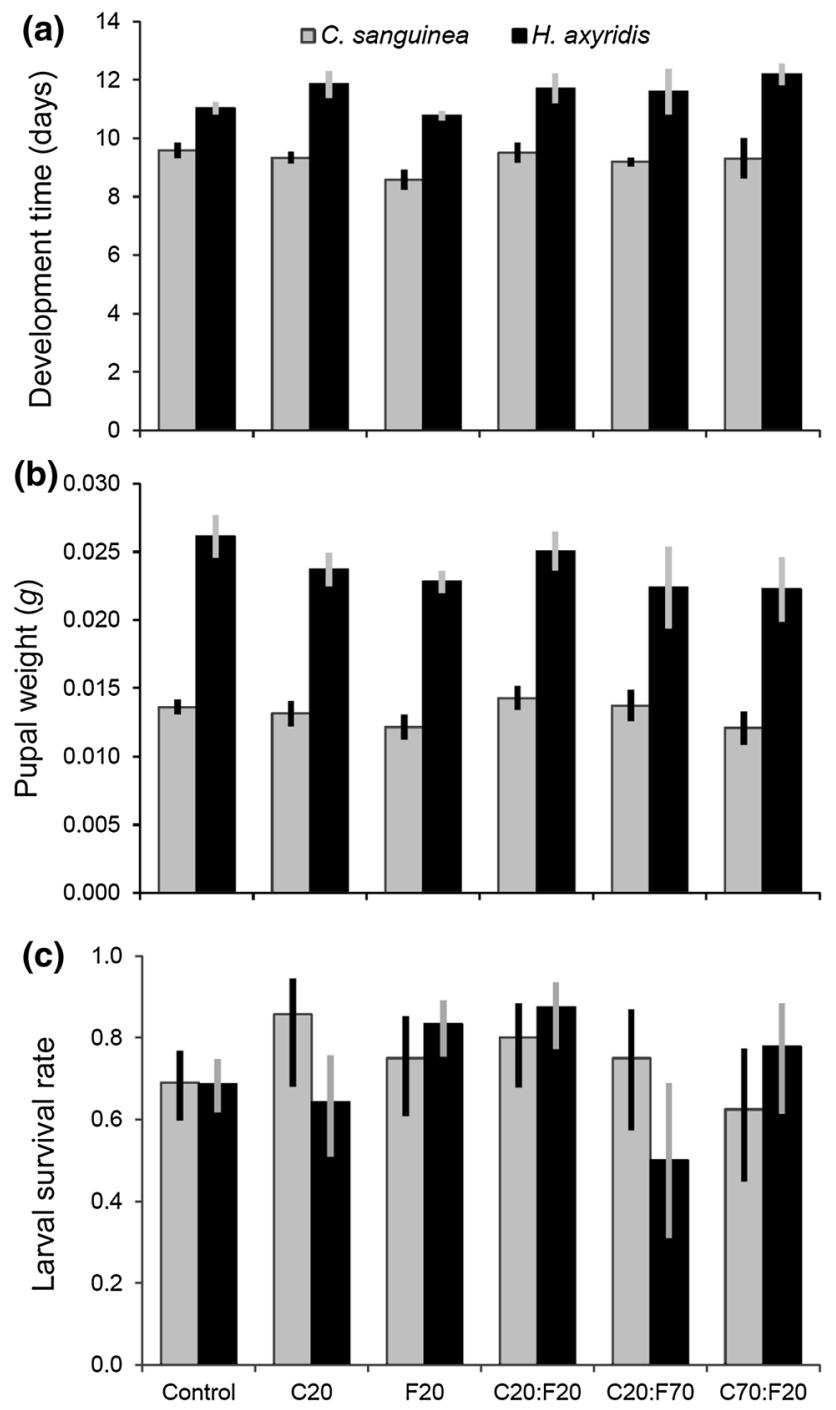

Fig. 5 Ecological performance of coccinellids exposed during the larval stage to aphids feeding on a liquid diet containing different concentrations of Cry1 Ac and Cry $1 \mathrm{~F}$, separately and combined: a development time (mean $\pm \mathrm{SE}$ ); b pupal weight (mean $\pm \mathrm{SE}$ ); c larval survival rate (mean $\pm \mathrm{SD}$ )

with caution. At the same time, future dose-response assays should be designed to test the modality of the biological response parameter. This will prevent faulty interpretations derived from bimodal biological responses among individuals from the same population, which could influence the conclusions about potential ecological effects. This variation might be a potential cause for why different research groups have reported contrasting findings from laboratory concentration-response experiments on the same species of natural enemy, even though these have been previously considered to be due to contamination, methodological differences, or methodological error (Romeis and Meissle 2011; Hilbeck et al. 2012; Romeis et al. 2012, 2014).

Regarding the interspecific differences between the predator species in uptake and bioaccumulation of Cry toxins, our study showed that the surrogate species methodology for studying potential ecological effects of Cry toxins on insect pest natural enemies should be used with caution. Despite being close relatives in the tribe Coccinellini, uptake was significantly higher in $H$. axyridis, both in the proportion of individuals and the concentrations per individual. The majority of $H$. axyridis took up both Cry toxins, and when they did, they bioaccumulated from their aphid food, especially on the F70 diet. In contrast, few C. sanguinea larvae took up either Cry toxin, and when uptake did occur, the concentration was low. This indicates that the lack of ecological effects in the two species stemmed from different mechanisms. The majority of $H$. axyridis were exposed both internally and in the gut, indicating that the absence of detectable effects is related to a lack of significant impacts on internal processes and in the gut. For $C$. sanguinea, the majority were exposed only in the gut, so absence of detectable effects may be related primarily to processes (or their absence) in the gut.

Superficially, the two species might have appeared to be reliable surrogates for each other because both had similar ecological effects (both lacked detectable effects), but in reality, the absences of detectable effects stemmed from very different biological mechanisms. A sine qua non condition for the use of surrogate species is that the species should respond to the toxin with similar physiological processes (Lewis 1995; Godoy et al. 2015), so the two species are not reliable surrogates for each other, and phylogenetic relatedness does not guarantee surrogacy for risk assessments of Cry toxins on non-target natural enemies. This surrogacy assumption needs to be examined more thoroughly for Cry toxins before non-target risk

Table 1 Estimated average dose of Cry toxin (ng) exposure to larval predators during their entire larval stage ( \pm SE) via aphids

\begin{tabular}{llll}
\hline Predator & Cry1Ac (ng) & Cry1F (F20, ng) & Cry1F (F70, ng) \\
\hline Cycloneda sanguinea & $1.57 \pm 0.19$ & $6.13 \pm 1.07$ & $37.65 \pm 3.09$ \\
Harmonia axyridis & $2.29 \pm 0.24$ & $8.91 \pm 1.39$ & $54.76 \pm 4.03$ \\
\hline
\end{tabular}

Calculated from the average Cry toxin concentration in aphids (ng/mg FW) and the average total number of aphids provided to the predators during larval development (mg FW) 
assessment methodologies based on it are widely adopted (e.g., Garcia-Alonso et al. 2006; Romeis et al. 2008).

On the other hand, it is impractical and unnecessary to test every non-target species from the local biodiversity. Instead, methods that do not rely on surrogacy should be used, such as an ecologically based method (Andow et al. 2013). This approach identifies the local biological diversity, classifies it into ecological functional groups, and selects key ecological functions for risk assessment. Nontarget species likely to be highly exposed to the environmental stressor and to contribute significantly to the ecological function are selected. For example, $C$. sanguinea is a common arthropod predator in cotton in Brazil (Faria et al. 2006) and provides important biological control of cotton aphids. As it is likely to be exposed to $B t$ cotton through bi- or tritrophic exposure, it could be used to evaluate the potential effects of $B t$ cotton on biological control agents in Brazil.

Acknowledgments We would like to thank H. F. van Emden, Michael Birkett, and Sarah Y. Dewhirst for the information regarding the artificial liquid diet and system to rear M. persicae; and Bruna Lima and Caroline A. Muniz for their assistance. This work was supported by Embrapa 02.11.07.003.00.00 Grant. A. B. received fellowship from LAC Biosafety project (GEF/World Bank Grant Numbers TF091844 and TF092071).

\section{Compliance with ethical standards}

Conflict of interest The authors declare no conflict of interest.

\section{References}

Andow DA, Lovei GL, Arpaia S, Wilson L, Fontes EMG, Hilbeck A, Lang A, Tuat NV, Pires CSS, Sujii ER, Zwahlen C, Birch ANE, Capalbo DMF, Prescott K, Omoto C, Zeilinger AR (2013) An ecologically-based method for assessing the risks to biological diversity from genetically-engineered plants. J Biosaf 22:141-156

Banks JE, Stark JD, Vargas RI, Achleh AS (2014) Deconstructing the surrogate species concept: a life history approach to the protection of ecosystem services. Ecol Appl 24:770-778

Bryan GW (1979) Bioaccumulation of marine pollutants. Philos Trans R Soc Lond Series B Biol Sci 286:483-505

Chapman RF (1998) The insects: structure and function, 4th edn. Cambridge University Press, Cambridge

Couty A, de la Viña G, Clark SJ, Kaiser L, Pham-Delègue M, Poppy GM (2001) Direct and indirect sublethal effects of Galanthus nivalis agglutinin (GNA) on the development of a potato-aphid parasitoid, Aphelinus abdominalis (Hymenoptera: Aphelinidae). J Ins Phys 47:553-561

Dadd RH, Mitter TE (1996) Permanent culture of an aphid on a totally synthetic diet. Experientia 22:832-833

Douglas AE, van Emden HF (2007) Nutrition and symbiosis. In: Van Emden HF, Harrington R (eds) Aphids as crop pests. CABI, Wallingford, pp 105-134

Elmegaard N, Jagers op Akkerhuis GAJM (2000) Safety factors in pesticide risk assessment. Differences in species sensitivity and acute-chronic relations. National Environmental Research Institute Technical Report 325
Faria MR, Lundgren JG, Fontes EMG, Fernandes OA, Schmidt F, Nguyen VT, Andow DA (2006) Assessing the effects of Bt cotton on generalist arthropod predators. In: Hilbeck A, Andow DA, Fontes EMG (eds) Environmental risk assessment of transgenic organisms: methodologies for assessing $B t$ cotton in Brazil. CAB International, Wallingford, pp 175-199

Gao M-Q, Hou S-P, Pu D-Q, et al (2010) Multi-generation effects of $\mathrm{Bt}$ rice on Anagrus nilaparvatae, a parasitoid of the nontarget pest Nilaparvata lugens. Environ Entomol 39:2039-2044

Garcia-Alonso M, Jacobs E, Raybould A, Nickson TE, Sowig P, Willekens H, van der Kouwe P, Layton R, Amijee F, Fuentes AM, Tencalla F (2006) A tiered system for assessing the risk of genetically modified plants to non-target organisms. Environ Biosaf Res 5:57-65

Giorgi JA, Vandenberg NJ, McHugh JV, Forrester JA, Slipinski SA, Miller KB, Shapiro LR, Whiting MF (2008) The evolution of food preferences in Coccinellidae. Biol Control 51:215-231

Godoy AA, Kummrow F, Pamplin PAZ (2015) Ecotoxicological evaluation of propranolol hydrochloride and losartan potassium to Lemna minor L. (1753) individually and in binary mixtures. Ecotoxicology 24:1112-1123

Groot AT, Dicke M (2002) Insect-resistant transgenic plants in a multi-trophic context. Plant J 31:387-406

Hilbeck A, McMillan JM, Meier M, Humbel A, Schläpfer-Miller J, Trtikova M (2012) A controversy re-visited: is the coccinellid Adalia bipunctata adversely affected by $B t$ toxins? Environ Sci Eur 24:10-22

Lewis MA (1995) Algae and vascular plant tests. In: Rand GM (ed) Fundamentals of aquatic toxicology-effects, environmental fate and risk assessment, 2nd edn. CRC Press, Washington, pp 135-169

Nakasu EYT, Dias SC, Pires CSS, Andow DA, Paula DP, Togni PHB, Macedo TR, Sujii ER, Sa MFG, Fontes EMG (2013) Bitrophic toxicity of Cry1Ac to Cycloneda sanguinea, a predator in Brazilian cotton. Ent Exp Appl 148:105-115

Paula DP, Andow DA (2015) Uptake and bioaccumulation of Cry toxins by an aphidophagous predator. Environ Pollut. doi:10. 1016/j.envpol.2015.11.036

Romeis J, Meissle M (2011) Non-target risk assessment of Bt cropsCry protein uptake by aphids. J Appl Entomol 135:1-6

Romeis J, Bartsch D, Bigler F, Candolfi MP, Gielkens MMC, Hartley SE, Hellmich RL, Huesing JE, Jepson PC, Layton R, Quemada H, Raybould A, Rose RI, Schiemann J, Sears MK, Shelton AM, Sweet J, Vaituzis Z, Wolt JD (2008) Assessment of risk of insect-resistant transgenic crops to nontarget arthropods. Nat Biotech 26:203-208

Romeis J, Alvarez-Alfageme F, Bigler F (2012) Putative effects of Cry $1 \mathrm{Ab}$ to larvae of Adalia bipunctata-reply to Hilbeck et al. (2012). Environ Sci Eur 24:18-23

Romeis J, Meissle M, Naranjo SE, Li Y, Bigler F (2014) The end of a myth-Bt $(\mathrm{Cry} 1 \mathrm{Ab})$ maize does not harm green lacewings. Front Plant Sci 5:391-401

Siebert MW, Patterson TG, Gilles GJ, Nolting SP, Braxton LB, Leonard BR, Van Duyn JW, Lassiter RB (2009) Quantification of Cry1Ac and Cry $1 \mathrm{~F}$ Bacillus thuringiensis insecticidal proteins in selected transgenic cotton plant tissue types. J Econ Entomol 102:1301-1308

Suter GW II (2007) Ecological risk assessment, 2nd edn. CRC Press, Boca Raton

USEPA (2013) Health effects glossary, glossary of health, exposure, and risk assessment terms and definitions of acronyms. http:// www.epa.gov/ttn/atw/hlthef/hapglossaryrev.html

Wright JP, Fisher DB, Mittler TE (1985) Measurement of feeding rates on artificial diets using ${ }^{3} \mathrm{H}$-inulin. Ent Exp Appl 37:9-11

Zhang G-F, Wan F-H, Lovei GL, et al (2006) Transmission of $B t$ toxin to the predator Propylaea japonica (Coleoptera: Coccinellidae) through its aphid prey feeding on transgenic Bt cotton. Environ Entomol 35:143-150 